\title{
A RETROSPECTIVE STUDY OF DURATION OF PHASE I OF DEXAMETHASONE-CYCLOPHOSPHAMIDE PULSE THERAPY IN PEMPHIGUS PATIENTS
}

\author{
Nayeem Sadath Haneef', Fathima Razvi², Bomma Yadagiri Praveen Kumar ${ }^{3}$, Nikhat ${ }^{4}$
}

1 Professor and HOD, Department of Dermatology, Venereology and Leprosy, Deccan College of Medical Sciences, Hyderabad. ${ }^{2}$ Associate Professor, Department of Dermatology, Venereology and Leprosy, Deccan College of Medical Sciences, Hyderabad. ${ }^{3}$ Assistant Professor, Department of Dermatology, Venereology and Leprosy, Deccan College of Medical Sciences, Hyderabad. ${ }^{4}$ Assistant Professor, Department of Dermatology, Venereology and Leprosy, Deccan College of Medical Sciences, Hyderabad.

ABSTRACT

\section{BACKGROUND}

Dexamethasone-Cyclophosphamide Pulse (DCP) therapy, consisting of 4 phases is very effective, safe and inexpensive treatment modality for pemphigus patients. There are very few studies on duration of phase I in pemphigus, which affects the total duration of DCP therapy.

\section{MATERIALS AND METHODS}

A 2-year retrospective analytical study was conducted to calculate duration of phase I of DCP therapy in 65 immunohistopathologically confirmed patients of pemphigus.

\section{RESULTS}

Duration of phase I was less than 6 months in 31 patients (47.69\%). It was 7 - 12 months in 27 patients (41.53\%). Just 7 patients $(10.76 \%)$ had to take phase I DCP for 12 - 18 months.

\section{CONCLUSION}

Duration of phase I of DCP was less than 12 months in majority of the patients (89.23\%). This duration was less in 6 months in close to $50 \%$ of the patients.

\section{KEYWORDS}

Pemphigus, DCP therapy, Dexamethasone-cyclophosphamide pulse therapy.

HOW TO CITE THIS ARTICLE: Haneef NS, Razvi F, Kumar BYP, et al. A retrospective study of duration of phase I of dexamethasone-cyclophosphamide pulse therapy in pemphigus patients. J. Evolution Med. Dent. Sci. 2017;6(20):1575-1577, DOI: $10.14260 /$ Jemds/2017/346

\section{BACKGROUND}

Pemphigus is a group of chronic autoimmune bullous mucocutaneous disorders, manifesting most commonly with blistering and erosions of the oral mucosa and/or skin. ${ }^{1}$ Pemphigus is caused by autoantibody (IgG) deposition against Desmoglein (1 and 3) antigens located in the desmosomes of epidermal keratinocytes or $9 \alpha$ nicotinic acetylcholine receptors, leading to acantholysis and intraepidermal cleft formation. ${ }^{2}$ It is the most common type of autoimmune disease in India unlike Western countries, where bullous pemphigoid is more common. ${ }^{3}$ It also occurs at much earlier age in India (Most patients belonging to less than 40 years of age) than the West ( 40 - 60 years' age group). ${ }^{4}$ There are various subtypes of this heterogeneous group, most common being pemphigus vulgaris. ${ }^{4}$ Other variants include pemphigus foliaceus, pemphigus vegetans, pemphigus erythematosus, paraneoplastic pemphigus, etc.

Pemphigus is a disease of high morbidity and mortality due to extensive erosions leading to acute skin failure.

Financial or Other, Competing Interest: None.

Submission 30-01-2017, Peer Review 12-02-2017,

Acceptance 15-02-2017, Published 09-03-2017.

Corresponding Author:

Dr. Nayeem Sadath Haneef,

\#3/102, Kalyani, Sahara States,

Mansoorabad, LB Nagar,

Hyderabad-50008, India.

E-mail: dr_nayeemsadath@yahoo.co.in

DOI: $10.14260 /$ jemds $/ 2017 / 346$
However, mortality rates have drastically reduced from $75 \%$ in pre-corticosteroid era to $25-45 \%$ after the advent of corticosteroids. $^{3}$ Subsequent introduction of immunosuppressive drugs like cyclophosphamide and azathioprine has helped the mortality rates to further decline to as less as $10 \% .^{3}$ Despite decline in mortality over the decades, pemphigus continues to be a troublesome disease due to its high morbidity and chronic course with frequent remissions and exacerbations without permanent cure in most patients. Treatment of this severe life-threatening mucocutaneous disease has been revolutionised by introduction of Dexamethasone-Cyclophosphamide Pulse (DCP) therapy by Pasricha and Gupta in 1981.5 DCP therapy has now become a well-established treatment modality in India in view of its lesser adverse effects and greater efficacy compared to conventional daily dose corticosteroid treatment. ${ }^{6}$ DCP therapy leads to long-term remission or even permanent cure in most patients of pemphigus. ${ }^{7}$ Dexamethasone-cyclophosphamide pulse therapy involves 4 phases. Patients receive injectable drugs in pulse doses as well as daily oral medication in phase I and II, whereas only daily oral treatment is given in phase III. Patients are followed up for any recurrences in phase IV without any active treatment. Phase I of DCP lasts till all the skin/mucosal lesions subside and hence the duration of this phase varies from as short as 2 months to as long as 4 years in different patients. ${ }^{3}$ The present study was undertaken to evaluate the duration of phase I as there is a paucity of literature on this parameter, which affects overall duration of DCP therapy. ${ }^{3}$ 


\section{MATERIALS AND METHODS Objective}

To evaluate the duration of phase I of Dexamethasonecyclophosphamide pulse therapy in patients of pemphigus.

\section{Study Design}

Retrospective data based analytical study.

\section{Setting}

Dermatology, Venereology and Leprosy Department of a Tertiary Care Hospital attached to a Postgraduate Training Institute in Telangana State of India.

\section{Period}

Two years (From 2014 to 2016).

\section{Inclusion Criteria}

65 patients of immuno-histopathologically confirmed pemphigus treated with DCP therapy were included in the study.

\section{Exclusion Criteria}

1. Patients treated with azathioprine instead of cyclophosphamide were excluded.

2. Patients who were treated with additional modalities such as rituximab were excluded.

\section{Treatment Protocol}

Dexamethasone-cyclophosphamide pulse therapy involved 4 phases. Phase I and II involved slow intravenous infusion (Over 2 - 3 hours) of dexamethasone $100 \mathrm{mg}$ (Suprapharmacological dose) in $500 \mathrm{~mL}$ of $5 \%$ dextrose on 3 consecutive days and $500 \mathrm{mg}$ cyclophosphamide on $2^{\text {nd }}$ day of the pulse and such pulses were repeated every 28 days. In between the pulses, oral cyclophosphamide was given in 50 mg once daily dose. Patients were considered to be in phase I till all the skin/mucosal lesions subsided without any further new lesions occurring and hence the duration of this phase varied in different patients. ${ }^{3}$ Phase II was given for a fixed duration of 9 months, where treatment given was similar to phase I. In phase III, the intravenous pulse consisting of dexamethasone and cyclophosphamide were stopped and only daily oral pulse of $50 \mathrm{mg}$ cyclophosphamide was given for 9 months. After this the patients were considered to have entered into phase IV, where all the drugs were stopped and the patients were followed up for as long as possible to observe for any possible recurrences. During all phases, secondary infections if any were treated with appropriate antibacterial, antifungal or other medications. Similarly, resultant adverse effects or electrolyte imbalances were managed appropriately.

\section{RESULTS}

Total of 65 patients fulfilling the inclusion criteria were recruited $(\mathrm{n}=65)$. Most patients (24 patients; $36.92 \%)$ belonged to 31 - 40 years' age group followed by 14 patients (21.53\%) in 51 - 60 years' age group (Table 1; Figure 1). Males were 25 (38.46\%) and 40 patients (61.53\%) were females (Table 2; Figure 2). Based on the characteristic clinical and immunofluorescence findings, 61 patients (93.84\%) were diagnosed as pemphigus vulgaris and 4 patients (6.15\%) had pemphigus foliaceus (Table 3; Figure 3). There were no patients of any other types of pemphigus in this study.
Duration of phase I of DCP therapy was calculated as time taken for all the oral/skin lesions to subside completely and no new lesions occur, after which the patients entered into phase II. Duration of phase I ranged from as short as 2 months to as long as 17 months. This duration was categorised into 3 categories for the sake of comparison. Duration of phase I was less than 6 months in 31 patients (47.69\%). It was $7-12$ months in 27 patients (41.53\%). Just 7 patients $(10.76 \%)$ had to take phase I DCP for $12-18$ months (Table 4; Figure 4). Even among these 7 patients who took more than 12 months for phase I, only 1 patient $(1.53 \%)$ had duration of 17 months and 2 patients (3.07\%) had a duration of 16 months, while other 4 patients had less than 14 months' duration. These findings indicate that duration of phase I of DCP was less than 12 months in majority of the patients $(89.23 \%)$.

\begin{tabular}{|c|c|c|}
\hline Age Group (Years) & No. of Patients & Percentage \\
\hline $1-10$ Years & 0 & $0 \%$ \\
\hline $11-20$ Years & 1 & $1.53 \%$ \\
\hline $21-30$ Years & 10 & $15.38 \%$ \\
\hline $31-40$ Years & 24 & $36.92 \%$ \\
\hline $41-50$ Years & 12 & $18.46 \%$ \\
\hline $51-60$ Years & 14 & $21.53 \%$ \\
\hline $61-70$ Years & 4 & $6.15 \%$ \\
\hline \multicolumn{2}{|c|}{ Table 1. Age Distribution (n= 65) } \\
\hline
\end{tabular}

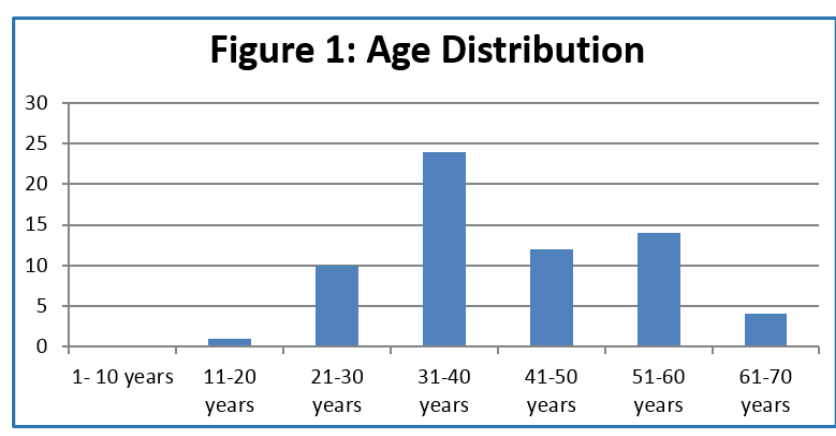

\begin{tabular}{|c|c|c|}
\hline Sex & No. of Patients & Percentage \\
\hline Male & 25 & $38.46 \%$ \\
\hline Female & 40 & $61.53 \%$ \\
\hline \multicolumn{2}{|c|}{ Table 2. Sex Distribution (n= 65) } \\
\hline
\end{tabular}

\section{Figure 2: Sex Distribution}

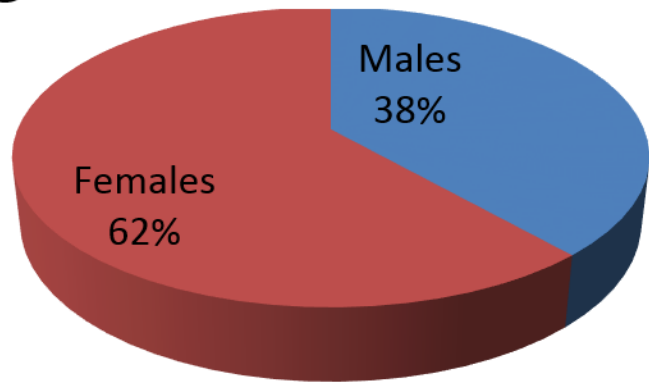

\begin{tabular}{|c|c|c|}
\hline Type of Pemphigus & No. of Patients & Percentage \\
\hline Pemphigus Vulgaris & 4 & $93.84 \%$ \\
\hline Pemphigus Foliaceus & 61 & $6.15 \%$ \\
\hline \multicolumn{2}{|c|}{ Table 3. Type of Pemphigus (n= 65) } \\
\multicolumn{2}{|r}{}
\end{tabular}




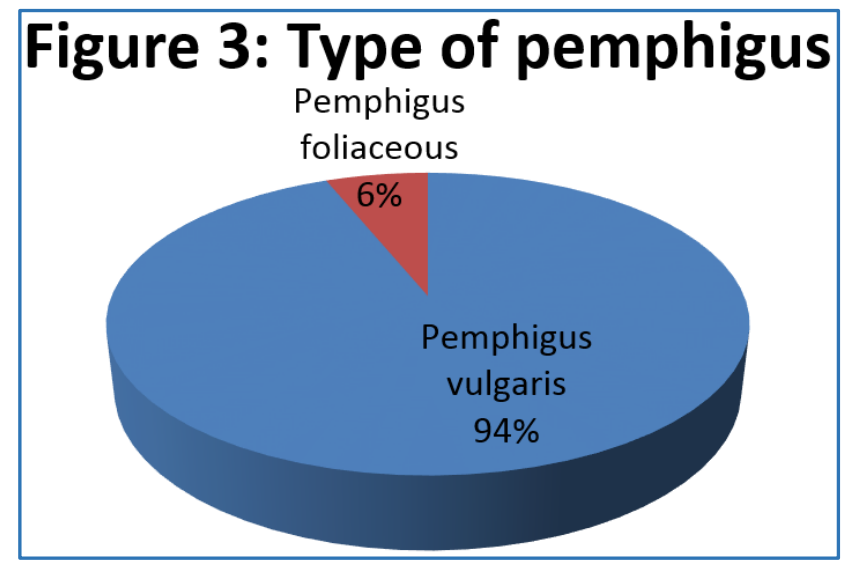

\begin{tabular}{|c|c|c|}
\hline Duration (Months) & No. of Patients & Percentage \\
\hline $1-6$ & 31 & $47.69 \%$ \\
\hline $7-12$ & 27 & $41.53 \%$ \\
\hline $12-18$ & 7 & $10.76 \%$ \\
\hline$>18$ & 0 & $0 \%$ \\
\hline Table 4. Duration of Phase I of DCP Therapy (n= 65) \\
\hline
\end{tabular}

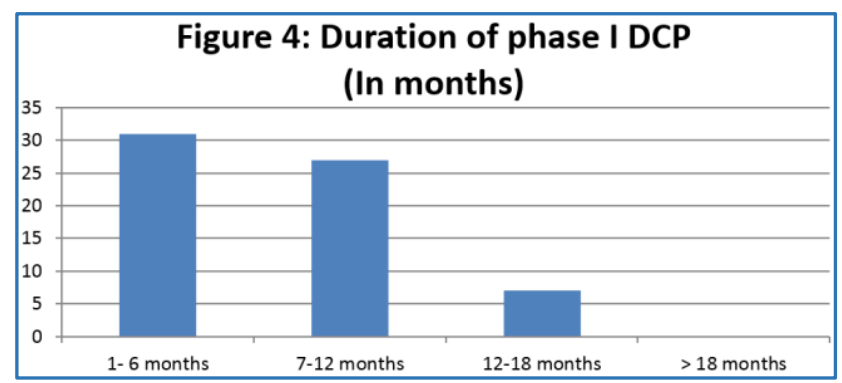

\section{DISCUSSION}

Dexamethasone-Cyclophosphamide Pulse (DCP) therapy has emerged as a very effective and relatively inexpensive treatment modality for pemphigus, which is a disease lasting for long duration associated with considerable morbidity and mortality.5,7 DCP is more effective and less expensive than methylprednisolone pulse therapy followed in the West.5,7 It is also associated with far fewer adverse effects compared to daily dose oral corticosteroid therapy. DCP, being a new therapy devised by Pasricha and Gupta in 1980s, has undergone several modifications regarding duration of its phases. But it has been universally accepted across all centres in India that phase I lasts till all the skin/mucosal lesions subside without any further new lesions occurring. ${ }^{3}$ Duration of phase I of DCP was found to be as short as 2 months to as long as 17 months in the present study, which is in coherence with findings of most other published data. ${ }^{3}$ It was found to be less than 12 months in majority of patients (89.23\%) in this study, which is also similar to studies by Pasricha et al, Kandan et al and Nayak et al.3,6,7 Kandan et al noted 11\% patients in their series required up to $16-20$ pulses. ${ }^{6}$ In our study, only $4.61 \%$ ( 3 patients) required 16 or maximum 17 pulses. Nayak et al studied potential factors affecting the duration of phase I including duration of disease, severity of disease, oral versus cutaneous involvement, concurrent administration of oral steroids, age or sex of the patients, etc. and found that disease severity at the onset of pulse therapy was the major factor affecting the duration of phase I of DCP. Our present study along with the afore-mentioned studies largely indicate that the duration of phase I of DCP is less than 12 months in majority of the patients, in fact being less than 6 months in about half the patients. This is significant since the duration of phase I of DCP affects the overall duration of active part of DCP therapy, as phase II and phase III are given for a constant duration of 9 months each. ${ }^{3}$ This important finding of usual duration of phase I of DCP therapy will help immensely in counselling the patients of pemphigus regarding expected total duration of therapeutically active phases (I, II and III) of DCP therapy.

\section{CONCLUSION}

Duration of phase I of DCP was less than 12 months in majority of the patients (89.23\%). This duration was less in 6 months in close to $50 \%$ of the patients.

\section{ACKNOWLEDGEMENTS}

We acknowledge Dr. A S Kumar, Former Professor and HOD of our Department for his invaluable contribution in establishing DCP therapy at our centre.

\section{REFERENCES}

[1] Huilgol SC, Black MM. Management of the immunobullous disorders. II. Pemphigus. Clin Exp Dermatol 1995;20(4):283-93.

[2] Grando SA. Pemphigus in 21st century: new life to an old story. Autoimmunity 2006;39(7):521-30.

[3] Nayak CS, Ray S, Thombre A, et al. Factors affecting the duration of phase I of dexamethasonecyclophosphamide pulse therapy. Indian J Dermatol Venereol Leprol 2014;80(4):296-9.

[4] Kanwar AJ, De D. Pemphigus in India. Indian J Dermatol Venereol Leprol 2011;77(4):439-49.

[5] Pasricha JS, Gupta R. Pulse therapy with dexamethasone cyclophosphamide in pemphigus. Ind J Dermatol Venereol Leprol 1984;50(5):199-203.

[6] Kandan S, Thappa DM. Outcome of dexamethasonecyclophosphamide pulse therapy in pemphigus: a case series. Indian J Dermatol Venereol Leprol 2009;75(4):373-8.

[7] Pasricha JS, Poonam. Current regimen of pulse therapy for pemphigus: minor modifications, improved results. Indian J Dermatol Venereol Leprol 2008;74(3):217-21. 